\title{
Comorbid Depression and Obesity: Correlates and Synergistic Association With Noncommunicable Diseases Among Australian Men
}

\author{
Tilahun Nigatu Haregu, $\mathrm{PhD}^{1}$; John Tayu Lee, $\mathrm{PhD}^{1}$; Brian Oldenburg, $\mathrm{PhD}^{1}$; Gregory Armstrong, $\mathrm{PhD}^{1}$
}

\begin{abstract}
Accessible Version: www.cdc.gov/pcd/issues/2020/19_0420.htm
Suggested citation for this article: Haregu TN, Lee JT, Oldenburg B, Armstrong G. Comorbid Depression and Obesity: Correlates and Synergistic Association With Noncommunicable Diseases Among Australian Men. Prev Chronic Dis 2020; 17:190420. DOI: https://doi.org/10.5888/pcd17.190420.
\end{abstract}

\section{PEER REVIEWED}

\section{Summary}

What is already known on this topic?

Depression and obesity are strongly related to each other.

What is added by this report?

A complex set of individual and area-level factors is associated with comorbid depression and obesity among men in Australia.

What are the implications for public health practice?

Evidence of correlates and synergistic association would be useful in designing integrated and focused health promotion interventions for Australian men.

\section{Abstract}

\section{Introduction}

Obesity and depression are among the leading causes of disease worldwide. Their bidirectional relationship often results in comorbid depression and obesity, which further increases the risk of adverse health outcomes. Further evidence is needed on the correlates and synergistic association with other noncommunicable diseases. The objective of our study was to examine the correlates and synergistic association of comorbid depression and obesity with other noncommunicable diseases in a large sample of Australian men.

\section{Methods}

Our cross-sectional study used data on 13,763 men aged 18 to 55 from the first wave (2013-2014) of the Australian Ten to Men study. Body mass index was calculated from self-reported weight and height. The Patient Health Questionnaire-9 was used to assess depression. We calculated the weighted prevalence of depression, obesity, and comorbid depression and obesity and examined correlates of comorbid depression and obesity by using logistic regression. We used the synergy index to measure the synergistic association of depression and obesity with other noncommunicable diseases.

\section{Results}

The weighted prevalence of depression, obesity, and comorbid depression and obesity among Australian men were $12.5 \%, 22.2 \%$, and $3.7 \%$, respectively. Age, marital status, area-level socioeconomic index, educational attainment, household income, employment status, and physical activity were significantly associated with comorbid depression and obesity. Men with comorbid depression and obesity, compared with men without comorbid depression and obesity, had 7.6 times the risk of diabetes and 6.7 times the risk of hypertension.

\section{Conclusion}

Co-occurrence of depression and obesity among Australian men is associated with a set of individual- and area-level correlates and a higher risk of noncommunicable diseases. The correlates identified in our study are useful in planning interventions and screening in primary care settings.

\section{Introduction}

The increasing burden of mental health disorders and obesity is a significant public health concern globally, including in Australia $(1,2)$. An estimated $45 \%$ of Australians experience a mental health condition in their lifetime (3). In any single year, about 1 million Australians have depression and about 2 million have anxiety (4). 
In 2017-2018, one in 5 Australians (20.1\%) had a mental or behavioral condition; approximately two-thirds (67.0\%) of Australian adults were either overweight or obese, and slightly less than onethird (31.3\%) were obese (3).

Depression and obesity often co-occur. A meta-analysis of 19 studies showed a bidirectional relationship between depression and obesity (5). In that study people who were depressed had a $37 \%$ increased risk of being obese, and people who were obese had an $18 \%$ increased risk of being depressed. Only 1 study from Australia, which examined the association between body mass index (BMI) and depression among young women, was included in this meta-analysis (6). A study of the prevalence of comorbid depression and obesity in Australian general practice reported a $U$ shape relationship between BMI and depression, with a higher prevalence of depression among underweight (23\%) and obese (24\%) adults (7).

Noncommunicable diseases (NCDs) account for $89 \%$ of premature deaths in Australia and are major contributors to socioeconomic inequality in health (8). NCDs, especially cardiovascular disease (CVD), share many common risk factors, including modifiable lifestyle factors such as unhealthy diet, physical inactivity, harmful use of alcohol, and tobacco use. Biomedical risk factors, such as high blood pressure, diabetes, dyslipidemia, and obesity, also contribute to the development and progression of CVD. About $38 \%$ of the prevalence of CVD in Australia is attributable to overweight and obesity (9).

About $38 \%$ of the total prevalence of illness in Australia is attributable to CVD risk factors, including overweight and obesity, which account for $8.4 \%$ of the total prevalence (10). Mental health disorders, such as depression and anxiety, also have a significant association with CVD $(11,12)$. As a result of interplay among these factors, at least $25 \%$ of Australians adults with mental health problems have chronic disease comorbidities (13).

Although the relationship between depression and obesity is considered bidirectional, the strength of the association is stronger from obesity to depression than from depression to obesity (14). In addition, sex and age moderate the relationship between depression and obesity. In a study conducted in Australia, the association was stronger among women than among men and among older people (15). The prevalence of comorbid depression was $24 \%$ among obese women and $21 \%$ among obese men. On the other hand, physical ill health is thought to mediate the relationship between obesity and depression (15).

The bidirectional relationship between depression and obesity is a public health concern because each disease alone and both diseases acting together have a strong negative effect on health and quality of life (16). Comorbid depression and obesity was shown to have a larger negative effect on quality of life than the sum of the independent effects of depression and obesity (17). The management of depression can affect obesity and vice versa. Controlled studies demonstrated that treatment of depression strongly affects body weight, although these findings are heterogeneous; the effect of treatment depends on type of antidepressant used and dose and duration of use (18).

Although the association between obesity and depression has been explored, evidence gaps still exist. First, most of the available evidence is based on studies conducted in clinical settings. As a result, limited evidence exists at community and general population levels, especially among adult men. This lack of data is important, because although the prevalence of depression is lower among men than among women in Australia, the prevalence of obesity is higher among men, and the effect of the interaction of these conditions on the risk of other NCDs has not been investigated (3).

Second, the combined effect of individual- and area-level correlates of comorbid depression and obesity have not been systematically investigated in Australia by using large population-based data sets. Third, the synergistic effects of depression and obesity on the risk of other NCDs have not been examined. Although depression and obesity are known risk factors for NCDs, we know little about their possible synergistic effect. Evidence is needed to inform prevention and treatment interventions.

Therefore, understanding the socioeconomic, behavioral, and environmental correlates of comorbid depression and obesity is essential to further understanding their complex relationship. The objective of our study was to describe individual- and area-level correlates of comorbid depression and obesity and examine their synergistic association with risk of other NCDs in a large sample of Australian men.

\section{Methods}

\section{Data source}

We used data from the first wave of the Australian Longitudinal Study on Male Health (the Ten to Men study). This ongoing longitudinal study, which uses a mailed survey, enables understanding of how changing life stages and circumstances affect the health and well-being of men and boys. Wave 1 recruitment occurred from October 2013 through July 2014; 15,988 males aged 10 to 55 years returned completed questionnaires. Our study group consisted of the 13,763 men among these who were aged 18 to 55 . Wave 1 of the Ten to Men study received ethical clearance from

The opinions expressed by authors contributing to this journal do not necessarily reflect the opinions of the U.S. Department of Health and Human Services, the Public Health Service, the Centers for Disease Control and Prevention, or the authors' affiliated institutions. 
the University of Melbourne Human Sciences Human Ethics SubCommittee. Participants aged 18 to 55 provided written consent. Wave 2 data were collected in 2015-2016.

A description of the cohort, methods, and sampling design in the Ten to Men study is available elsewhere (19-21). The study has a stratified, multistage, cluster sampling design and oversamples in rural and regional areas. Wave 1 included 432 Aboriginal and Torres Strait Islander people. The study questionnaire included variables on sociodemographic characteristics, geographic location, physical and emotional health, use of health care services, health behaviors, risk and protective factors, personal and family situation, life stages and life events, and social and environmental factors.

\section{Variables and measurement}

The questionnaire for the first wave of the Ten to Men study is available online (https://tentomen.org.au/sites/default/files/adult_ survey_final_with_variable_names.pdf). The key variables of interest in our study were obesity and depression. We used BMI (body weight in kilograms divided by height in meters squared $\left.\left[\mathrm{kg} / \mathrm{m}^{2}\right]\right)$, calculated from self-reported body weight and standing height, to measure obesity. We classified men with a BMI of 30 $\mathrm{kg} / \mathrm{m}^{2}$ or more as obese. For depression, the Ten to Men study used the Patient Health Questionnaire (PHQ-9), which assesses depression on the basis of 9 symptoms (22). The questionnaire scores each of the 9 symptoms on a frequency scale from 0 (not at all) to 3 (nearly every day), and the sum of the scores determines the presence and the degree of depression. We considered a PHQ9 score of 10 or more to indicate moderate-to-severe depression. Other variables included in our analysis were sociodemographic factors (age, marital status, educational attainment, employment status, and combined annual household income), area-level factors (using the Socio-Economic Indexes for Areas [SEIFA] [23] to measure socioeconomic advantage and disadvantage), behavioral factors (current smoking, alcohol misuse [using the Alcohol Use Disorders Identification Test (24)]), physical activity (using Australia's Physical Activity and Sedentary Behavior Guidelines for Adults [25]), number of fruit and vegetable servings per day, and the presence of NCDs other than obesity and depression: CVD (hypertension, myocardial infarction, heart failure, stroke, angina), diabetes, cancer, chronic respiratory diseases (chronic obstructive pulmonary disease, chronic bronchitis, asthma), cataracts, high cholesterol, and arthritis. The Ten to Men study assessed the presence of NCDs by using 2 questions: "Has a doctor or other health professional ever told you that you had this condition?" and "Have you been treated for or had any symptoms of this condition in the past 12 months?" We used data from the second question in our study. We measured all variables at the individual and household level, except for SEIFA and annual household income, which we measured at the area and household level, respectively.

\section{Data analysis}

We summarized the weighted prevalence of depression, obesity, and comorbid depression and obesity by sociodemographic characteristics. We used sampling weights, computed by the Ten to Men study, according to the inverse probability of selection (26). We examined correlates of depression, obesity, and comorbid depression and obesity by using multiple logistic regression models. We tabulated adjusted odds ratios (ORs) and 95\% confidence intervals (CIs) for correlates of depression, obesity, and comorbid depression and obesity. To assess the effect of SEIFA (in percentiles) on the correlates of comorbid depression and obesity, we conducted stratified analysis by SEIFA quartiles (first quartile, 1-28; second quartile, 29-51, third quartile, 52-69, fourth quartile, 70-100). In this index, the higher the score, the greater the socioeconomic advantage. We used the synergy index (17) to assess the synergistic effect of depression and obesity on the risk of other NCDs. We calculated the synergy index as the ratio of the combined effects of comorbid depression and obesity to the sum of the individual effects of depression and obesity (27). We calculated $95 \%$ CIs for the synergy index by using the delta method. This method used a standard error of the synergy index that was derived from the regression coefficients and covariance of the effects of depression, obesity, and comorbid depression and obesity on each of the NCDs. We tested for multicollinearity of all covariates; the variance inflation factors were all less than 5, indicating that the assumption of reasonable independence among predictor variables was met. We analyzed all data in Stata version 15.0 (StataCorp LLC).

\section{Results}

About half (51.8\%) of 13,763 men in our study were younger than 40 (Table 1). Almost two-thirds (65.3\%) were married. Onequarter $(24.9 \%)$ had less than a high school diploma, and $15.7 \%$ were unemployed at the time of the survey. One in $5(19.2 \%)$ men were current smokers, 2 in $5(38.4 \%)$ misused alcohol, and 2 in 3 $(66.8 \%)$ had inadequate consumption of fruit and vegetables.

One in $8(12.5 \%)$ men had depression. About 1 in $5(22.2 \%)$ were obese. Nearly one-third (31.2\%) of men with depression were obese, and $16.8 \%$ of men who were obese had depression. The weighted prevalence of comorbid depression and obesity was $3.7 \%$.

The opinions expressed by authors contributing to this journal do not necessarily reflect the opinions of the U.S. Department of Health and Human Services, the Public Health Service, the Centers for Disease Control and Prevention, or the authors' affiliated institutions. 


\section{Correlates of comorbid depression and obesity}

The risk of depression decreased with age, whereas the risk of obesity increased with age. Higher educational attainment was associated with a lower risk of depression. Unemployment was associated with higher risk of depression. The prevalence of comorbid depression and obesity was significantly higher among men aged 30 to 39,40 to 49 , and 50 to 55 than among men aged 18 to 29 . Being single or never married, being in the first SEIFA quartile, and being sedentary were significantly associated with higher risk of comorbid depression and obesity (Table 2).

The stratified analyses across SEIFA quartiles showed that age, employment status, and physical activity were consistently and significantly associated with comorbid depression and obesity across all quartiles. Married men had reduced risk of comorbid depression and obesity compared with never-married men in lower SEIFA quartiles. Higher educational attainment was significantly associated with reduced risk of comorbidity in the first and third SEIFA quartiles. Similarly, higher income was also associated with reduced risk of comorbidity in the third and fourth SEIFA quartiles (Table 3 ).

\section{Synergistic association of depression and obesity with other NCDs}

We found a strong positive association between comorbid depression and obesity and the risk of other NCDs. Men with comorbid depression and obesity had 7.6 times the risk of diabetes, 6.7 times the risk of hypertension, and 4.3 times the risk of high cholesterol, compared with men without comorbid depression and obesity. The analysis of synergistic effects showed a $68 \%$ excess risk of diabetes, $57 \%$ excess risk of hypertension, and more than twice the excess risk of arthritis and high cholesterol among men with comorbid depression and obesity, compared with the sum of the independent risks from depression and obesity (Table 4).

The predicted prevalence of NCDs was higher among men with comorbid depression and obesity than among men that had neither condition, men who had depression only, and men who had obesity only (Figure). The prevalence of hypertension, high cholesterol, asthma, and arthritis was higher than the prevalence of other chronic conditions included in our analysis. Stratification of these effects by SEIFA quartiles showed that the effects were higher in low SEIFA quartiles, especially for stroke, hypertension, arthritis, and high cholesterol.

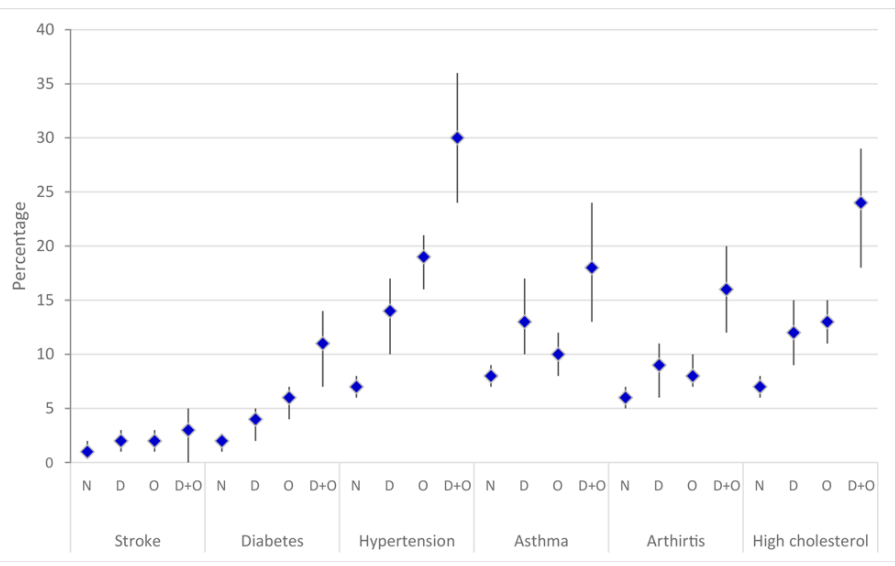

Figure. Predicted prevalence of noncommunicable diseases by neither condition (N), depression only (D), obesity only (O), and depression and obesity $(D+0)$ among men aged 18-55 participating in wave 1 of the Ten to Men study on male health in Australia, 2013-2014. Error bars indicate 95\% confidence intervals.

\section{Discussion}

We found a $3.7 \%$ overall prevalence of comorbid depression and obesity among Australian men aged 18 to 55 years. However, we observed a higher prevalence (31.2\%) of obesity among men with depression than among men in the entire study population $(18.5 \%)$. We also found a set of factors associated with comorbid depression and obesity. Age, employment status, and physical activity were consistently associated with comorbid depression and obesity across all levels of socioeconomic status categories. Moreover, we demonstrated a significant association between comorbid depression and obesity and excess risk of other NCDs.

A systematic review and meta-analysis of 9 studies reported that people with obesity were $32 \%$ (36\% among women and $8 \%$ among men) more likely than people with normal BMI to have depression (28). Our study found a $62 \%$ increased risk of depression among men who were obese. The difference in findings between the systematic review and our study could be due to several factors. The 9 studies in the systematic review were from the United States, Canada, and Norway. They included both men and women and used different scales to assess depression. Our study was limited to Australian men and used the PHQ-9 to assess depression. One study in the systematic review used the PHQ-9 to assess depression in the National Health and Nutrition Examination Survey and estimated a 2.5 times higher risk among adults with obesity (29), higher than our estimate of risk. The difference between estimates could be due to differences in population characteristics.

\footnotetext{
The opinions expressed by authors contributing to this journal do not necessarily reflect the opinions of the U.S. Department of Health and Human Services, the Public Health Service, the Centers for Disease Control and Prevention, or the authors' affiliated institutions.
} 
The prevalence of depression among obese patients was reported to be $23 \%$ in a study of general practice clinics in Australia (7). Our study found a $17 \%$ prevalence of depression among obese men. Although the study populations differed, both studies used the PHQ-9 to assess depression, and the prevalence in the study of obese patients in general practice is not too far off the prevalence found in our study. In Mexico, a study that used the Hamilton Depression Rating Scale to assess depression in patients with type 2 diabetes reported a nearly $50 \%$ prevalence among obese patients (30). This higher prevalence could be due to the effect of type 2 diabetes on depression.

Our study found that older age and unemployment were associated with a higher risk of comorbid depression and obesity. We also showed a decline in the risk of depression but an increase in the risk of obesity as age increased. This finding is consistent with the findings reported by other studies $(31,32)$. The higher risk of comorbid depression and obesity among unemployed men than among employed men in this study could have been due to the stronger effect of unemployment on the risk of depression among men with obesity than among men without obesity.

On the other hand, our study showed that higher educational attainment was associated with lower risk of obesity and comorbid depression and obesity. However, some studies indicated that high educational attainment was associated with greater risk of comorbid depression and obesity, with prominent effects among women (33). This difference could be related to the stronger relationship between depression and obesity among women than among men. Higher household income was negatively associated with depression and comorbid depression and obesity. Similar studies reported higher levels of mental health disorders among people with low educational attainment and low household income (34).

In our study, physical activity was associated with a lower risk of depression, obesity, and comorbid depression and obesity. This finding is consistent with findings from other studies that show the negative effects of depression on physical activity, which in turn increases the risk of obesity $(35,36)$. However, we did not find any significant associations between smoking, alcohol use, or consumption of fruit and vegetables and comorbid depression and obesity.

In addition to the individual-level correlates, the area-level factor, SEIFA, was significantly associated with the risk of obesity and comorbid depression and obesity. Men in the lower SEIFA quartiles had a higher prevalence of depression, obesity, and comorbid depression and obesity. Similar studies in Australia reported a higher risk of obesity among socially disadvantaged people (37). The effect of SEIFA on risk of comorbid depression and obesity needs to be further explored, because other factors may explain this association.

In this study, we found a significant association between comorbid depression and obesity and excess risk of other NCDs, such as diabetes, hypertension, and high cholesterol. This association was moderated by socioeconomic status. The excess risk of other NCDs among men with comorbid depression and obesity has implications for public health: prevention, early detection, and management of NCDs are needed for men with this comorbidity. Evidence of correlates and synergistic association would be useful in designing integrated and focused health promotion interventions However, further research, preferably longitudinal research, is needed to investigate the synergistic effect of depression and obesity on the risk of other NCDs.

Our study had several limitations. First, because the study design was cross-sectional, we could not establish a sequence of events for the onset of depression, obesity, and other NCDs. Establishing this sequence would affect the direction of the association between depression and obesity. Second, the Ten to Men study was not designed to study comorbid depression and obesity or its effects on the risk of other NCDs. Consequently, the number of men with other NCDs was small, and this small number affected the power of the study, especially for determining the significance of the synergy index. Third, self-reported weight and height were used to calculate BMI, which is less accurate than height and weight measured by health care professionals. Similarly, depression was assessed by using the PHQ-9, which is based on self-report. Although this scale is well validated, the possibility of social desirability bias cannot be ruled out. Finally, this study focused on men, and the findings cannot be generalized to the overall population or women.

Our study found that the overall prevalence of comorbid depression and obesity among Australian men was 3.7\%. Comorbid depression and obesity among Australian men was associated with a set of individual-level sociodemographic factors, including age, marital status, educational attainment, household income, and employment status. Among the behavioral factors studied, physical activity was significantly associated with comorbid depression and obesity. We also found an inverse association between SEIFA, an area-level factor, and comorbid depression and obesity. Comorbid depression and obesity was associated with excess risk of other NCDs. Moreover, we showed that comorbid depression and obesity was associated with a risk of NCDs that was higher than the risk found by summing the independent effects of depression and obesity. The correlates identified in our study are useful in planning interventions and screening in primary care settings. Further research is needed to explain the mechanisms that underpin these relationships.

The opinions expressed by authors contributing to this journal do not necessarily reflect the opinions of the U.S. Department of Health and Human Services, the Public Health Service, the Centers for Disease Control and Prevention, or the authors' affiliated institutions. 


\section{Acknowledgments}

Survey data for this article were collected by The University of Melbourne as part of the Australian Longitudinal Study on Male Health, funded by the Australian Government Department of Health. We are grateful to the boys and men who provided these survey data. No copyrighted materials were used in the conduct of this research or the writing of this article.

\section{Author Information}

Corresponding Author: Tilahun Nigatu Haregu, PhD, Nossal Institute for Global Health, Level 5, 333 Exhibition St, Melbourne, Victoria 3000. Email: haregu.t@unimelb.edu.au.

Author Affiliations: ${ }^{1}$ Nossal Institute for Global Health, School of Population and Global Health, University of Melbourne, Melbourne, Australia.

\section{References}

1. Rehm J, Shield KDJ. Global burden of disease and the impact of mental and addictive disorders. Curr Psychiatry Rep 2019; 21(2):10.

2. Reilly JJ, El-Hamdouchi A, Diouf A, Monyeki A, Somda SA. Determining the worldwide prevalence of obesity. Lancet 2018;391(10132):1773-4.

3. Australian Bureau of Statistics. National Health Survey: first results, 2017-18. Canberra (AU): Australian Bureau of Statistics; 2018. https://www.abs.gov.au/ausstats/abs@.nsf/mf/ 4364.0.55.001. Accessed March 4, 2020.

4. Australian Bureau of Statistics. National Health Survey, first results, -Australia 2014-15. Canberra (AU): Australian Bureau of Statistics; 2015. https://www.ausstats.abs.gov.au/ $\mathrm{a} u \mathrm{~s} s \mathrm{t}$ a t s / s u b s c r i b e r. n s f/ $0 /$ CDA 852 A 349 B 4CEE6CA257F 150009 FC53/\$File/ national $\% 20$ health $\% 20$ survey $\% 20$ first $\% 20$ results, $\% 202014$ 15.pdf. Accessed March 4, 2020.

5. Mannan M, Mamun A, Doi S, Clavarino A. Is there a bidirectional relationship between depression and obesity among adult men and women? Systematic review and bias-adjusted meta analysis. Asian J Psychiatr 2016;21:51-66.

6. Ball K, Burton NW, Brown WJ. A prospective study of overweight, physical activity, and depressive symptoms in young women. Obesity (Silver Spring) 2009;17(1):66-71.

7. Carey M, Small H, Yoong SL, Boyes A, Bisquera A, SansonFisher R. Prevalence of comorbid depression and obesity in general practice: a cross-sectional survey. Br J Gen Pract 2014; 64(620):e122-7.
8. World Health Organization. Noncommunicable diseases (NCD) country profiles. Geneva $(\mathrm{CH})$ : World Health Organization; 2018.

9. Australian Institute of Health and Welfare. Impact of overweight and obesity as a risk factor for chronic conditions: Australian Burden of Disease Study. Canberra (AU): Australian Institute of Health and Welfare; 2017.

10. Australian Institute of Health and Welfare. Australian Burden of Disease Study: impact and causes of illness and death in Australia 2015 - summary report. Canberra (AU): Australian Institute of Health and Welfare; 2019.

11. Cohen BE, Edmondson D, Kronish IM. State of the art review: depression, stress, anxiety, and cardiovascular disease. Am J Hypertens 2015;28(11):1295-302.

12. Batelaan NM, Seldenrijk A, Bot M, van Balkom AJ, Penninx BW. Anxiety and new onset of cardiovascular disease: critical review and meta-analysis. Br J Psychiatry 2016 ; 208(3):223-31.

13. Caughey GE, Vitry AI, Gilbert AL, Roughead EE. Prevalence of comorbidity of chronic diseases in Australia. BMC Public Health 2008;8(1):221.

14. Faith MS, Butryn M, Wadden TA, Fabricatore A, Nguyen AM, Heymsfield SB. Evidence for prospective associations among depression and obesity in population-based studies. Obes Rev 2011;12(5):e438-53.

15. Jorm AF, Korten AE, Christensen H, Jacomb PA, Rodgers B, Parslow RA. Association of obesity with anxiety, depression and emotional well-being: a community survey. Aust N Z J Public Health 2003;27(4):434-40.

16. Mendlewicz J. The broad spectrum of comorbid depression: implications for treatment. Eur Psychiatry 1998;13(1):1-8.

17. Nigatu YT, Reijneveld SA, de Jonge P, van Rossum E, Bültmann U. The combined effects of obesity, abdominal obesity and major depression/anxiety on health-related quality of life: the LifeLines Cohort Study. PLoS One 2016; 11(2):e0148871.

18. Sevilla-González MDR, Quintana-Mendoza BM, AguilarSalinas CA. Interaction between depression, obesity, and type 2 diabetes: a complex picture. Arch Med Res 2017; 48(7):582-91.

19. Pirkis J, Currier D, Carlin J, Degenhardt L, Dharmage SC, Giles-Corti B, et al. Cohort profile: Ten to Men (the Australian Longitudinal Study on Male Health). Int J Epidemiol 2017; 46(3):793-794i.

20. Currier D, Pirkis J, Carlin J, Degenhardt L, Dharmage SC, Giles-Corti B, et al. The Australian Longitudinal Study on Male Health — methods. BMC Public Health 2016;16(Suppl 3):1030.

The opinions expressed by authors contributing to this journal do not necessarily reflect the opinions of the U.S. Department of Health and Human Services, the Public Health Service, the Centers for Disease Control and Prevention, or the authors' affiliated institutions. 
21. Pirkis J, Macdonald J, English DR. Introducing Ten to Men, the Australian longitudinal study on male health. BMC Public Health 2016;16(Suppl 3):1044.

22. Kroenke K, Spitzer RL, Williams JB. The PHQ-9: validity of a brief depression severity measure. J Gen Intern Med 2001; 16(9):606-13.

23. Australian Bureau of Statistics. Socio-Economic Indexes for Areas: introduction, use and future directions. ABS Catalogue no. 1351.0.55.015. Canberra (AU): Australian Bureau of Statistics; 2006.

24. Fawcett JE, Shakeshaft AP, Harris MF, Wodak A, Mattick RP, Richmond RL. Using AUDIT to classify patients into Australian Alcohol Guideline categories. Med J Aust 2004; 180(11):598.

25. Government of Australia, The Department of Health. Australia's physical activity and sedentary behaviour guidelines and the Australian 24-hour movement guidelines. https://www1.health.gov.au/internet/main/publishing.nsf/ Content/health-pubhlth-strateg-phys-act-guidelines\#npa1864. Accessed February 18, 2020.

26. Spittal MJ, Carlin JB, Currier D, Downes M, English DR, Gordon I, et al. The Australian longitudinal study on male health sampling design and survey weighting: implications for analysis and interpretation of clustered data. BMC Public Health 2016;16(Suppl 3):1062.

27. Knol MJ, VanderWeele TJ, Groenwold RHH, Klungel OH, Rovers MM, Grobbee DE. Estimating measures of interaction on an additive scale for preventive exposures. Eur J Epidemiol 2011;26(6):433-8.

28. Pereira-Miranda E, Costa PRF, Queiroz VAO, Pereira-Santos M, Santana MLP. Overweight and obesity associated with higher depression prevalence in adults: a systematic review and meta-analysis. J Am Coll Nutr 2017;36(3):223-33.

29. Zhao G, Ford ES, Li C, Tsai J, Dhingra S, Balluz LS. Waist circumference, abdominal obesity, and depression among overweight and obese U.S. adults: National Health and Nutrition Examination Survey 2005-2006. BMC Psychiatry 2011;11(1):130.

30. Martínez Hernández F, Tovilla Zárate CA, López Narváez L, Juárez Rojop IE, Jiménez Santos MA, González Gutiérrez CP, et al. [Prevalence and gravity of depression and anxiety in patients with obesity and type 2 diabetes: a study in the population of Tabasco, Mexico]. Gac Med Mex 2014; 150(Suppl 1):101-6.

31. Wild B, Herzog W, Schellberg D, Lechner S, Niehoff D, Brenner $\mathrm{H}$, et al. Association between the prevalence of depression and age in a large representative German sample of people aged 53 to 80 years. Int J Geriatr Psychiatry 2012; 27(4):375-81.
32. Jura M, Kozak LP. Obesity and related consequences to ageing. Age (Dordr) 2016;38(1):23.

33. Preiss K, Brennan L, Clarke D. A systematic review of variables associated with the relationship between obesity and depression. Obes Rev 2013;14(11):906-18.

34. Sareen J, Afifi TO, McMillan KA, Asmundson GJG. Relationship between household income and mental disorders: findings from a population-based longitudinal study. Arch Gen Psychiatry 2011;68(4):419-27.

35. Chekroud SR, Gueorguieva R, Zheutlin AB, Paulus M, Krumholz HM, Krystal JH, et al. Association between physical exercise and mental health in 1.2 million individuals in the USA between 2011 and 2015: a cross-sectional study. Lancet Psychiatry 2018;5(9):739-46.

36. Bauman AE, Grunseit AC, Rangul V, Heitmann BL. Physical activity, obesity and mortality: does pattern of physical activity have stronger epidemiological associations? BMC Public Health 2017;17(1):788.

37. Ghosh A, Charlton KE, Batterham MJ. Socioeconomic disadvantage and its implications for population health planning of obesity and overweight, using cross-sectional data from general practices from a regional catchment in Australia. BMJ Open 2016;6(5):e010405.

The opinions expressed by authors contributing to this journal do not necessarily reflect the opinions of the U.S. Department of Health and Human Services, the Public Health Service, the Centers for Disease Control and Prevention, or the authors' affiliated institutions. 


\section{Tables}

Table 1. Self-Reported Characteristics of Men Aged 18 to 55 Participating in Wave 1 of the Australian Longitudinal Study on Male Health (Ten to Men Study) ( $\mathrm{N}=$ 13,763), October 2013-July 2014

\begin{tabular}{|c|c|c|c|c|}
\hline Characteristic/Factor & Depression Only & Obesity Only & $\begin{array}{c}\text { Comorbid Depression } \\
\text { and Obesity }\end{array}$ & Total $(95 \% \mathrm{Cl})$ \\
\hline No. (\% of study population) & $982(8.2)$ & $2,461(18.5)$ & $510(3.7)$ & - \\
\hline \multicolumn{5}{|c|}{ Sociodemographic Characteristics } \\
\hline \multicolumn{5}{|l|}{ Age, y } \\
\hline $18-29$ & $11.0(9.6-12.5)$ & $11.1(9.7-12.6)$ & $2.5(1.9-3.3)$ & $25.1(24.1-26.1)$ \\
\hline 30-39 & $8.3(6.9-9.8)$ & $16.0(14.5-17.6)$ & $3.8(3.0-4.7)$ & $26.7(25.7-27.7)$ \\
\hline $40-49$ & $6.4(5.5-7.5)$ & $23.5(21.7-25.3)$ & $4.1(3.4-4.9)$ & $30.6(29.5-31.7)$ \\
\hline $50-55$ & $7.8(6.3-9.6)$ & $23.1(20.9-25.6)$ & $4.7(3.7-5.8)$ & $17.6(16.8-18.5)$ \\
\hline \multicolumn{5}{|l|}{ Marital status } \\
\hline Never married & $12.5(11.0-14.2)$ & $13.2(11.7-14.9)$ & $4.6(3.7-5.6)$ & $28.0(27.0-29.1)$ \\
\hline Divorced/widowed/separated & $14.3(11.5-17.7)$ & $20.7(17.3-24.7)$ & $7.1(5.3-9.6)$ & $6.6(6.1-7.2)$ \\
\hline Currently married & $6.0(5.3-6.7)$ & $20.4(19.3-21.5)$ & $3.1(2.6-3.5)$ & $65.3(64.2-66.5)$ \\
\hline \multicolumn{5}{|l|}{ Educational attainment } \\
\hline$\leq$ High school & $11.5(10.0-13.3)$ & $20.2(18.3-22.2)$ & $5.9(4.9-7.1)$ & $24.9(23.9-25.9)$ \\
\hline Diploma or certificate & $8.4(7.4-9.5)$ & $21.6(20.2-23.1)$ & $4.0(3.4-4.8)$ & $43.2(42.0-44.4)$ \\
\hline Bachelor's degree or above & $5.5(4.5-6.7)$ & $12.8(11.5-14.4)$ & $1.8(1.4-2.5)$ & $30.1(29.0-31.2)$ \\
\hline Other & $11.5(7.0-18.2)$ & $19.6(11.9-30.5)$ & $5.5(3.0-9.7)$ & $1.9(1.6-2.2)$ \\
\hline \multicolumn{5}{|c|}{ Combined annual household income, $A \$$} \\
\hline$<40,000$ & $21.1(17.5-25.2)$ & $17.2(14.3-20.5)$ & $7.9(6.1-10.1)$ & $11.4(10.6-12.2)$ \\
\hline $40,000-79,999$ & $9.1(7.8-10.6)$ & $18.9(17.1-20.9)$ & $5.4(4.5-6.6)$ & $26.7(25.6-27.8)$ \\
\hline$\geq 80,000$ & $5.2(4.6-6.0)$ & $19.2(18.0-20.4)$ & $2.5(2.1-3.0)$ & $61.9(60.7-63.1)$ \\
\hline \multicolumn{5}{|l|}{ Employment status } \\
\hline Employed & $6.4(5.8-7.0)$ & $18.7(17.8-19.7)$ & $2.8(2.5-3.3)$ & $84.3(83.4-85.2)$ \\
\hline Unemployed & $19.3(16.5-22.4)$ & $16.9(14.5-19.6)$ & $9.3(7.7-11.1)$ & $15.7(14.8-16.6)$ \\
\hline \multicolumn{5}{|c|}{ Lifestyle and Behavioral Factors } \\
\hline \multicolumn{5}{|l|}{ Current smoking } \\
\hline No & $6.5(5.9-7.2)$ & $18.7(17.7-19.7)$ & $3.3(2.9-3.8)$ & $80.8(79.9-81.7)$ \\
\hline Yes & $16.0(13.9-18.3)$ & $17.3(15.4-19.4)$ & $5.6(4.6-6.8)$ & $19.2(18.3-20.1)$ \\
\hline \multicolumn{5}{|l|}{ Alcohol misuse } \\
\hline No & $6.9(6.1-7.9)$ & $19.3(18.1-20.6)$ & $3.3(2.8-3.8)$ & $61.6(60.4-62.7)$ \\
\hline Yes & $9.6(8.6-10.7)$ & $18.0(16.5-19.6)$ & $4.2(3.5-5.0)$ & $38.4(37.3-39.6)$ \\
\hline
\end{tabular}

a Values are weighted \% (95\% Cl) unless otherwise noted.

"Survey participants answered the following yes-no question: "Have you been treated for or had any symptoms of this condition in the past 12 months?"

${ }^{c}$ The study used the Patient Health Questionnaire (PHQ-9) to assess depression on the basis of 9 symptoms (22). The questionnaire scores each of the 9 symptoms on a frequency scale from 0 (not at all) to 3 (nearly every day), and the sum of the scores determines the presence and the degree of depression. We considered a PHQ-9 score of 10 or more to indicate moderate-to-severe depression.

${ }^{\mathrm{d}}$ We used BMI, calculated from self-reported body weight and standing height (body weight in $\mathrm{kg}$ divided by height in meters squared [kg/ $\left.\mathrm{m}^{2}\right]$ ), to measure obesity. (continued on next page)

The opinions expressed by authors contributing to this journal do not necessarily reflect the opinions of the U.S. Department of Health and Human Services, the Public Health Service, the Centers for Disease Control and Prevention, or the authors' affiliated institutions. 
(continued)

Table 1. Self-Reported Characteristics of Men Aged 18 to 55 Participating in Wave 1 of the Australian Longitudinal Study on Male Health (Ten to Men Study) ( $\mathrm{N}=$ 13,763), October 2013-July $2014^{\mathrm{a}}$

\begin{tabular}{|c|c|c|c|c|}
\hline Characteristic/Factor & Depression Only & Obesity Only & $\begin{array}{c}\text { Comorbid Depression } \\
\text { and Obesity }\end{array}$ & Total $(95 \% \mathrm{Cl})$ \\
\hline Adequate $(\geq 5)$ & $9.0(8.2-10.0)$ & $18.8(17.8-20.0)$ & $4.0(3.6-4.6)$ & $33.2(32.2-34.3)$ \\
\hline Inadequate $(<5)$ & $6.7(5.8-7.8)$ & $17.7(16.2-19.3)$ & $3.1(2.5-3.9)$ & $66.8(65.7-67.8)$ \\
\hline \multicolumn{5}{|l|}{ Physical activity, per week } \\
\hline Sedentary (0 min and 0 sessions) & $10.2(8.3-12.4)$ & $25.7(22.9-28.7)$ & $8.2(6.6-10.3)$ & $13.6(12.8-14.4)$ \\
\hline Insufficiently active ( $<150 \mathrm{~min}$ or $<5$ sessions) & $9.3(7.9-10.9)$ & $20.0(18.2-21.8)$ & $4.9(4.1-5.9)$ & $29.1(28.0-30.2)$ \\
\hline Sufficiently active ( $>150 \mathrm{~min}$ in $>5$ sessions) & $7.0(6.3-7.9)$ & $16.7(15.5-18.0)$ & $2.4(2.0-2.9)$ & $57.4(56.2-58.6)$ \\
\hline \multicolumn{5}{|l|}{ Chronic conditions $^{b}$} \\
\hline Depression (PHQ-9 $\geq 10)^{\mathrm{C}}$ & - & $31.2(28.2-34.2)$ & - & $12.5(11.8-13.3)$ \\
\hline Obesity $\left(\mathrm{BMI} \geq 30 \mathrm{~kg} / \mathrm{m}^{2}\right)^{\mathrm{d}}$ & $16.8(15.2-18.6)$ & - & - & $22.2(21.3-23.2)$ \\
\hline Cardiovascular disease or stroke & $2.7(1.8-4.1)$ & $2.4(1.7-3.4)$ & $5.6(3.4-9.0)$ & $1.7(1.4-2.1)$ \\
\hline Diabetes & $3.8(2.7-5.2)$ & $6.6(5.4-8.1)$ & $14.4(10.9-18.7)$ & $3.2(2.8-3.6)$ \\
\hline Hypertension & $11.7(9.3-14.5)$ & $20.5(18.4-22.7)$ & $32.7(27.7-38.2)$ & $9.9(9.3-10.6)$ \\
\hline Asthma & $14.8(12.2-18.0)$ & $9.6(8.2-11.1)$ & $20.3(15.9-25.6)$ & $9.1(8.5-9.8)$ \\
\hline Arthritis & $10.9(8.5-13.9)$ & $9.5(8.0-11.3)$ & $19.4(15.2-24.4)$ & $6.9(6.4-7.6)$ \\
\hline High cholesterol & $9.4(7.6-11.6)$ & $13.8(12.0-15.8)$ & $26.1(21.3-31.5)$ & $8.8(8.1-9.5)$ \\
\hline
\end{tabular}

a Values are weighted \% (95\% Cl) unless otherwise noted.

'Survey participants answered the following yes-no question: "Have you been treated for or had any symptoms of this condition in the past 12 months?"

${ }^{\mathrm{C}}$ The study used the Patient Health Questionnaire (PHQ-9) to assess depression on the basis of 9 symptoms (22). The questionnaire scores each of the 9 symptoms on a frequency scale from 0 (not at all) to 3 (nearly every day), and the sum of the scores determines the presence and the degree of depression. We considered a PHQ-9 score of 10 or more to indicate moderate-to-severe depression.

${ }^{\mathrm{d}}$ We used BMI, calculated from self-reported body weight and standing height (body weight in $\mathrm{kg}$ divided by height in meters squared $\left[\mathrm{kg} / \mathrm{m}^{2}\right]$ ), to measure obesity. 
Table 2. Prevalence and Correlates of Depression, Obesity, and Comorbid Depression and Obesity Among Men Aged 18 to 55 Participating in Wave 1 of the Australian Longitudinal Study on Male Health (Ten to Men Study) $(\mathrm{N}=13,763)$, October 2013-July $2014^{\mathrm{a}}$

\begin{tabular}{|c|c|c|c|}
\hline Characteristic/Factor & Depression Only & Obesity Only & $\begin{array}{c}\text { Comorbid Depression and } \\
\text { Obesity }\end{array}$ \\
\hline \multicolumn{4}{|c|}{ Sociodemographic Characteristics } \\
\hline \multicolumn{4}{|l|}{ Age, y } \\
\hline $18-29$ & $1.00[$ Reference $]$ & $1.00[$ Reference] & 1.00 [Reference] \\
\hline 30-39 & $0.86(0.64-1.16)[.32]$ & $1.47(1.14-1.91)[.004]$ & $4.46(2.60-7.66)[<.001]$ \\
\hline $40-49$ & $0.68(0.50-0.91)[.01]$ & $2.34(1.82-3.01)[<.001]$ & $4.58(2.59-8.09)[<.001]$ \\
\hline $50-55$ & $0.61(0.43-0.86)[.005]$ & $2.22(1.7-2.91)[<.001]$ & $4.53(2.50-8.21)[<.001]$ \\
\hline \multicolumn{4}{|l|}{ Marital status } \\
\hline Never married & $1.00[$ Reference] & $1.00[$ Reference] & 1.00 [Reference] \\
\hline Divorced/widowed/separated & $1.36(0.93-1.98)[.11]$ & $0.90(0.63-1.30)[.59]$ & $0.71(0.40-1.25)[.23]$ \\
\hline Currently married & $0.78(0.60-1.02)[.07]$ & $1.04(0.82-1.31)[.78]$ & $0.48(0.31-0.75)[.001]$ \\
\hline \multicolumn{4}{|l|}{ Educational attainment } \\
\hline$\leq$ High school & $1.00[$ Reference $]$ & $1.00[$ Reference] & $1.00[$ Reference $]$ \\
\hline Diploma or certificate & $0.92(0.72-1.16)[.48]$ & $0.91(0.76-1.10)[.35]$ & $0.72(0.51-1.01)[.06]$ \\
\hline Bachelor's degree or above & $0.75(0.55-1.05)[.09]$ & $0.60(0.48-0.75)[<.001]$ & $0.42(0.27-0.67)[<.001]$ \\
\hline Other & $1.18(0.71-1.98)[.52]$ & $0.96(0.42-2.18)[.92]$ & $1.06(0.46-2.45)[.89]$ \\
\hline \multicolumn{4}{|c|}{ Combined annual household income, $\mathrm{A} \$$} \\
\hline$<40,000$ & $1.00[$ Reference $]$ & $1.00[$ Reference] & 1.00 [Reference] \\
\hline $40,000-79,999$ & $0.69(0.50-0.94)[.02]$ & $1.15(0.82-1.61)[.42]$ & $0.82(0.49-1.38)[.46]$ \\
\hline$\geq 80,000$ & $0.48(0.34-0.66)[<.001]$ & $1.22(0.88-1.68)[.24]$ & $0.54(0.32-0.93)[.03]$ \\
\hline \multicolumn{4}{|l|}{ Employment status } \\
\hline Employed & $1.00[$ Reference] & $1.00[$ Reference] & $1.00[$ Reference $]$ \\
\hline Unemployed & $2.87(2.17-3.78)[<.001]$ & $1.09(0.82-1.45)[.56]$ & $3.33(2.25-4.93)[<.001]$ \\
\hline \multicolumn{4}{|l|}{ SEIFA quartiles ${ }^{b}$} \\
\hline First & $1.00[$ Reference $]$ & $1.00[$ Reference] & $1.00[$ Reference $]$ \\
\hline Second & $1.03(0.78-1.35)[.85]$ & $0.81(0.66-1.00)[.048]$ & $0.95(0.64-1.40)[.80]$ \\
\hline Third & $0.84(0.62-1.12)[.23]$ & $0.75(0.61-0.93)[.007]$ & $0.85(0.58-1.27)[.43]$ \\
\hline Fourth & $0.96(0.72-1.27)[.76]$ & $0.54(0.44-0.68)[<.001]$ & $0.36(0.23-0.56)[<.001]$ \\
\hline \multicolumn{4}{|c|}{ Lifestyle and Behavioral Factors } \\
\hline \multicolumn{4}{|l|}{ Current smoking } \\
\hline No & $1.00[$ Reference] & $1.00[$ Reference] & 1.00 [Reference] \\
\hline Yes & $1.68(1.33-2.12)[<.001]$ & $0.85(0.69-1.04)[.12]$ & $0.81(0.55-1.17)[.26]$ \\
\hline \multicolumn{4}{|l|}{ Alcohol misuse } \\
\hline No & $1.00[$ Reference] & $1.00[$ Reference] & $1.00[$ Reference] \\
\hline Yes & $1.43(1.16-1.76)[.001]$ & $0.94(0.80-1.10)[.44]$ & $1.26(0.92-1.73)[.15]$ \\
\hline
\end{tabular}

${ }^{a}$ All values are odds ratio (95\% confidence interval) [ $P$ value]. All odds ratios were adjusted for other characteristics included in this table. Except for SEIFA quartiles, all data were self-reported.

${ }^{b}$ We used the Socio-Economic Indexes for Areas (SEIFA) to measure socioeconomic status (23). Data were stratified by SEIFA quartiles (first quartile, 1-28; second quartile, 29-51, third quartile, 52-69, fourth quartile, 70-100). In this index, the higher the score (and quartile), the greater the socioeconomic advantage.

The opinions expressed by authors contributing to this journal do not necessarily reflect the opinions of the U.S. Department of Health and Human Services, the Public Health Service, the Centers for Disease Control and Prevention, or the authors' affiliated institutions. 
(continued)

Table 2. Prevalence and Correlates of Depression, Obesity, and Comorbid Depression and Obesity Among Men Aged 18 to 55 Participating in Wave 1 of the Australian Longitudinal Study on Male Health (Ten to Men Study) $(\mathrm{N}=13,763)$, October 2013-July $2014^{\mathrm{a}}$

\begin{tabular}{|c|c|c|c|}
\hline Characteristic/Factor & Depression Only & Obesity Only & $\begin{array}{l}\text { Comorbid Depression and } \\
\text { Obesity }\end{array}$ \\
\hline \multicolumn{4}{|l|}{ Fruit and vegetable intake, servings per day } \\
\hline Adequate $(\geq 5)$ & 1.00 [Reference] & $1.00[$ Reference] & 1.00 [Reference] \\
\hline Inadequate $(<5)$ & $1.13(0.90-1.42)[.30]$ & $1.04(0.89-1.22)[.59]$ & $1.10(0.79-1.53)[.57]$ \\
\hline \multicolumn{4}{|l|}{ Physical activity, per week } \\
\hline Sedentary ( 0 min and 0 sessions) & 1.00 [Reference] & $1.00[$ Reference] & 1.00 [Reference] \\
\hline Insufficiently active ( $<150 \mathrm{~min}$ or $<5$ sessions) & $0.87(0.65-1.16)[.34]$ & $0.78(0.62-0.98)[.04]$ & $0.59(0.40-0.87)[.008]$ \\
\hline Sufficiently active ( $>150 \mathrm{~min}$ in $>5$ sessions) & $0.63(0.47-0.84)[.001]$ & $0.68(0.55-0.84)[<.001]$ & $0.27(0.17-0.41)[<.001]$ \\
\hline
\end{tabular}

${ }^{a}$ All values are odds ratio (95\% confidence interval) [ $P$ value]. All odds ratios were adjusted for other characteristics included in this table. Except for SEIFA quartiles, all data were self-reported.

${ }^{\mathrm{b}}$ We used the Socio-Economic Indexes for Areas (SEIFA) to measure socioeconomic status (23). Data were stratified by SEIFA quartiles (first quartile, 1-28; second quartile, 29-51, third quartile, 52-69, fourth quartile, 70-100). In this index, the higher the score (and quartile), the greater the socioeconomic advantage. 
Table 3. Correlates of Comorbid Depression and Obesity, by SEIFA Quartiles, ${ }^{a}$ Among Men Aged 18 to 55 Participating in Wave 1 of the Australian Longitudinal Study on Male Health (Ten to Men Study) $(\mathrm{N}=13,763)$, October 2013-July $2014^{\mathrm{b}}$

\begin{tabular}{|c|c|c|c|c|}
\hline Characteristic/Factor & 1st Quartile & 2nd Quartile & 3rd Quartile & 4th Quartile \\
\hline \multicolumn{5}{|l|}{ Age, y } \\
\hline $18-29$ & $1.00[$ Reference] & $1.00[$ Reference] & $1.00[$ Reference] & 1.00 [Reference] \\
\hline 30-39 & $4.32(1.84-10.16)[.001]$ & $3.54(1.12-11.21)[.03]$ & $5.30(1.62-17.32)[.006]$ & $5.69(1.20-27.02)$ [.03] \\
\hline $40-49$ & $2.61(1.06-6.40)[.04]$ & $6.36(1.98-20.39)[.002]$ & $5.69(1.57-20.60)[.008]$ & $7.69(1.58-37.29)$ [.01] \\
\hline $50-55$ & $4.33(1.74-10.76)[.002]$ & $5.67(1.73-18.59)[.004]$ & $3.56(0.94-13.50)[.06]$ & $5.28(0.98-28.56)$ [.05] \\
\hline \multicolumn{5}{|l|}{ Marital status } \\
\hline Never married & $1.00[$ Reference] & $1.00[$ Reference] & $1.00[$ Reference] & 1.00 [Reference] \\
\hline Previously married & $0.67(0.30-1.52)[.34]$ & $0.51(0.16-1.61)[.25]$ & $0.89(0.26-3.06)[.86]$ & $1.81(0.39-8.36)[.44]$ \\
\hline Currently married & $0.51(0.27-0.97[.04]$ & $0.40(0.17-0.96)[.04]$ & $0.51(0.18-1.46)[.21]$ & $0.42(0.13-1.31)[.13]$ \\
\hline \multicolumn{5}{|l|}{ Educational attainment } \\
\hline$\leq$ High school & $1.00[$ Reference] & $1.00[$ Reference] & $1.00[$ Reference] & 1.00 [Reference] \\
\hline Diploma or certificate & $0.75(0.42-1.33)[.32]$ & $0.97(0.53-1.80)[.93]$ & $0.61(0.31-1.19)[.15]$ & $0.45(0.15-1.30)[.14]$ \\
\hline Bachelor's degree or above & $0.32(0.12-0.84)[.02]$ & $0.73(0.33-1.61)[.43]$ & $0.31(0.13-0.77)[.01]$ & $0.41(0.14-1.16)[.09]$ \\
\hline Other & $0.77(0.13-4.48)[.77]$ & $1.05(0.25-4.49)[.94]$ & $4.08(1.01-16.41)[.048]$ & $-^{\mathrm{c}}$ \\
\hline \multicolumn{5}{|l|}{ Combined annual household income, $A \$$} \\
\hline$<40,000$ & $1.00[$ Reference] & 1.00 [Reference] & $1.00[$ Reference] & 1.00 [Reference] \\
\hline $40,000-79,999$ & $1.04(0.48-2.23)[.92]$ & $1.25(0.49-3.15)[.64]$ & $0.51(0.17-1.54)[.23]$ & $0.20(0.05-0.91)[.04]$ \\
\hline$\geq 80,000$ & $0.55(0.23-1.30)[.17]$ & $0.80(0.32-1.97)[.62]$ & $0.32(0.10-1.01)[.05]$ & $0.59(0.18-1.95)[.39]$ \\
\hline \multicolumn{5}{|l|}{ Employment status } \\
\hline Employed & $1.00[$ Reference] & $1.00[$ Reference $]$ & $1.00[$ Reference] & 1.00 [Reference] \\
\hline Unemployed & $3.06(1.64-5.71)[<.001]$ & $3.70(1.76-7.78)[.001]$ & $3.42(1.47-7.92)[.004]$ & $4.71(1.68-13.21)[.003]$ \\
\hline \multicolumn{5}{|l|}{ Current smoking } \\
\hline No & $1.00[$ Reference] & $1.00[$ Reference] & $1.00[$ Reference] & 1.00 [Reference] \\
\hline Yes & $0.89(0.53-1.50)[.66]$ & $0.70(0.36-1.38)[.30]$ & $1.06(0.43-2.60)[.90]$ & $0.58(0.20-1.69)[.32]$ \\
\hline \multicolumn{5}{|l|}{ Alcohol misuse } \\
\hline No & $1.00[$ Reference $]$ & $1.00[$ Reference $]$ & $1.00[$ Reference] & 1.00 [Reference] \\
\hline Yes & $1.05(0.61-1.81)[.86]$ & $1.07(0.56-2.05)[.84]$ & $1.58(0.80-3.09)[.18]$ & $1.73(0.82-3.63)[.15]$ \\
\hline \multicolumn{5}{|l|}{ Fruit and vegetable intake, servings per day } \\
\hline$\geq 5$ & $1.00[$ Reference] & $1.00[$ Reference] & $1.00[$ Reference] & 1.00 [Reference] \\
\hline$<5$ & $0.79(0.45-1.40)[.43]$ & $1.20(0.60-2.41)[.60]$ & $1.67(0.87-3.17)[.12]$ & $1.47(0.68-3.16)[.32]$ \\
\hline \multicolumn{5}{|l|}{ Physical activity } \\
\hline Sedentary ( 0 min and 0 sessions) & $1.00[$ Reference] & $1.00[$ Reference $]$ & $1.00[$ Reference] & $1.00[$ Reference $]$ \\
\hline Insufficiently active (<150 min or $<5$ sessions) & $0.62(0.32-1.23)[.17]$ & $0.36(0.18-0.73)[.004]$ & $0.58(0.28-1.20)[.14]$ & $0.84(0.30-2.35)[.74]$ \\
\hline Sufficiently active (>150 $\mathrm{min}$ in $>5$ sessions) & $0.26(0.12-0.56)[.001]$ & $0.28(0.14-0.60)[.001]$ & $0.27(0.12-0.58)[.001]$ & $0.17(0.05-0.55)[.003]$ \\
\hline
\end{tabular}

The opinions expressed by authors contributing to this journal do not necessarily reflect the opinions of the U.S. Department of Health and Human Services, the Public Health Service, the Centers for Disease Control and Prevention, or the authors' affiliated institutions. 
Table 4. Association Between Comorbid Depression and Obesity and Other Noncommunicable Diseases Among Men Aged 18 to 55 Participating in Wave 1 of the Australian Longitudinal Study on Male Health (Ten to Men Study) $(\mathrm{N}=13,763)$, October 2013-July 2014

\begin{tabular}{|c|c|c|}
\hline Noncommunicable Disease & Odds Ratio (95\% Confidence Interval) [ $P$ Value] & Synergy Index (95\% Confidence Interval) $)^{\mathrm{b}}$ \\
\hline \multicolumn{3}{|l|}{ Cardiovascular disease/stroke } \\
\hline Depressive symptoms only & $1.54(0.75-3.16)[.24]$ & - \\
\hline Obesity only & $1.25(0.71-2.20)[.45]$ & - \\
\hline Depressive symptoms and obesity & $1.86(0.70-5.00)[.22]$ & $1.10(0.11-11.31)$ \\
\hline \multicolumn{3}{|l|}{ Diabetes } \\
\hline Depressive symptoms only & $2.26(1.19-4.28)[.01]$ & - \\
\hline Obesity only & $3.67(2.44-5.53)[<.001]$ & - \\
\hline Depressive symptoms and obesity & $7.62(4.51-12.87)[<.001]$ & $1.68(0.92-3.08)$ \\
\hline \multicolumn{3}{|l|}{ Hypertension } \\
\hline Depressive symptoms only & $2.29(1.61-3.26)[<.001]$ & - \\
\hline Obesity only & $3.36(2.69-4.19)[<.001]$ & - \\
\hline Depressive symptoms and obesity & $6.74(4.73-9.60)[<.001]$ & $1.57(1.02-2.44)$ \\
\hline \multicolumn{3}{|l|}{ Asthma } \\
\hline Depressive symptoms only & $1.81(1.29-2.52)[.001]$ & - \\
\hline Obesity only & $1.36(1.08-1.72)[.01]$ & - \\
\hline Depressive symptoms and obesity & $2.69(1.81-4.00)[<.001]$ & $1.45(0.66-3.19)$ \\
\hline \multicolumn{3}{|l|}{ Arthritis } \\
\hline Depressive symptoms only & $1.42(0.94-2.13)[.09]$ & - \\
\hline Obesity only & $1.35(1.03-1.77)[.03]$ & - \\
\hline Depressive symptoms and obesity & $3.02(2.07-4.40)[<.001]$ & $2.62(0.98-7.01)$ \\
\hline \multicolumn{3}{|l|}{ High cholesterol } \\
\hline Depressive symptoms only & $1.72(1.18-2.51)[.004]$ & - \\
\hline Obesity only & $1.90(1.48-2.43)[<.001]$ & - \\
\hline Depressive symptoms and obesity & $4.31(2.93-6.34)[<.001]$ & $2.04(1.11-3.75)$ \\
\hline \multicolumn{3}{|c|}{$\begin{array}{l}\text { a Outcome variables were each of the noncommunicable diseases. Main predictor was combination of depression and obesity. All models were adjusted for the } \\
\text { Socio-Economic Indexes for Areas (23), age, income, marital status, educational attainment, smoking, alcohol, physical activity, and employment. } \\
{ }^{b} \text { The synergy index shows the excess risk from comorbid depression and obesity when compared with the sum of independent risks from depression and obesity. } \\
\text { For example, a synergy index of } 2 \text { means the risk of high cholesterol among men with comorbid depression and obesity is } 2 \text { times the sum of independent risks } \\
\text { from depression and obesity. }\end{array}$} \\
\hline
\end{tabular}

The opinions expressed by authors contributing to this journal do not necessarily reflect the opinions of the U.S. Department of Health and Human Services, the Public Health Service, the Centers for Disease Control and Prevention, or the authors' affiliated institutions. 